\title{
RESQUÍCIOS DE CURT NIMUENDAJÚ
}

Patrícia Bayod Donatti ${ }^{1}$

\section{RESUMO}

Esse texto faz uma crítica as ideias do antropólogo/arqueólogo Curt Nimuendajú que são rememoradas por acadêmicos e não acadêmicos como herói, sem discutir as políticas de extermínio as quais ele esteve ligado. Utilizo o prisma do Holocausto para refletir sobre o genocídio nativo levado a cabo no Brasil até os dias atuais.

Palavras-chave: Nimuendajú, resquícios, memória, política, genocídio

\section{ABSTRACT}

This article criticezes Nimuendajú ideas that remains from academic and non-academic millieu about the german anthropologist/ archaeologist as a hero and does not discuss the genocide politics. I utilized the prisma of Holocausto for analysing the destruction of native people in Brazil until nowadays.

Keywords: Nimuendajú, remnants, memory, media, politic, genocide

\section{RESUMEN}

Este articulo critica las ideas del antropólogo/arqueólogo Curt Nimuendajú. Recordado por académicos y no-académicos como um heróe, fueron dejando fuera de discusión sus influencias em politicas de extermínio. Utilizo el prisma del Holocausto para reflexionar sobre el genocídio indígena, llevado adelante em Brasil hasta los días de hoy.

Palabras clave: Nimunedajú, restos, memoria, media, política, genocidio

\section{Introdução}

O alemão Curt Unkel Nimuendajú (Figura 1) é considerado um antropólogo/arqueólogo central para se entender as políticas da Antropologia/Arqueologia no Brasil (DONATTI, 2013). Muitas pesquisas foram geradas sobre seu trabalho e sua vida por diversos pesquisadores que o elogiaram. Por exemplo, Gastão Cruls (1944), Herbert Baldus (1946), Nunes Pereira (1946), Egon Schaden (1953), Robert Lowie (1959), Claude Lévi-Strauss (1983), Expedito Arnaud (1983-1984), Eduardo Viveiros de Castro (NIMUENDAJÚ, 1987), Roque de Barros Laraia (1988), Roberto Cardoso de Oliveira (CORREA, 1991), Ronaldo Vainfas (1995), César Gordon Jr (1996), Luis Donizete Grupioni (1998), João Pacheco de Oliveira Filho (1999), Tekla Hartmann (NIMUENDAJÚ, 2000),

1 Pesquisadora independente. Mestra em Arqueologia pelo MAE/USP. Contato: patbayod@hotmail.com 


\section{Revista de Arqueologia Pública}

Elena Monteiro Welper (2002- 2013), Per Stenborg (NIMUENDAJÚ, 2004), Priscila Faulhauber (2013), Peter Shcröder (2013).

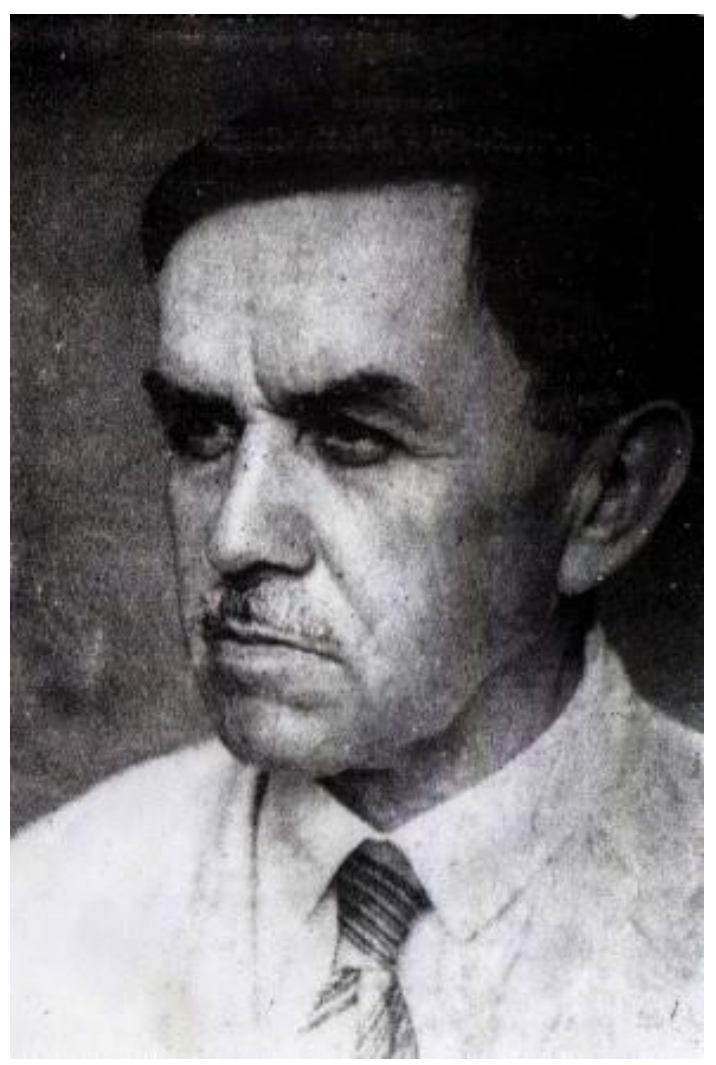

Figura 1: Curt Nimuendajú. Rio de Janeiro, 1945. ((PEREIRA, 1946, s.p.; WELPER, 2002, s.p; DONATTI, 2013, 281)

A importância de seu trabalho é refletida na sociedade e na academia em diversas formas, como em placas de ruas; rua Curt Nimuendajú do bairro Perdizes em São Paulo ou a rua Kurt Nimuendaju, no bairro Paulista em Piracicaba, também através de seu nome dado ao laboratório de Arqueologia da Universidade Federal do Oeste do Pará- Santarém, e à antiga sala de objetos arqueológicos e etnográficos do Museu de Gothemburgo, cujo diretor Nordenskiold, no passado, em homenagem ao antropólogo, a denominou "Sala Nimuendajú". Mais ainda, um filme de animação denominado "Nimuendajú" está em fase de produção, mostrando que a mídia tem resgatado o valor do nome Nimuendajú.

"Nimuendajú" foi o nome que Curt Unkel se apropriou durante sua estadia na comunidade Apopocuva Guarani, no ano de 1905 (DONATTI 2013; UNKEL 1987). Ao longo da vida, assina todos os seus trabalhos sobre os nativos do Brasil com seu pseudônimo, omitindo o sobrenome alemão Unkel (DONATTI, 2013). 


\section{Revista de Arqueologia Pública}

Desde sua chegada ao Brasil, em 1903, vindo de Jena, na Alemanha, até sua morte em 1945, no Amazonas, Curt Unkel produziu um material enorme de publicações, principalmente descritivas, sobre os nativos (GRUPIONI, 1998; WELPER, 2002-2013; DONATTI, 2013; FAULHAUBER, 2013; SCHRÖDER, 2013). Tornou-se um grande etnólogo embora sem formação para tal (DONATTI, 2013). Esteve sempre ligado ao Estado, às práticas de pacificação às populações nativas e à venda de coleções arqueológicas e etnográficas para os museus europeus e brasileiros (DONATTI, 2013).

Recebeu financiamento do Estado brasileiro e de países interessados no colecionismo, como Alemanha, Suécia, França, Estados Unidos, onde estão seus arquivos (GRUPIONI, 1998; DONATTI, 2013; SCHRÖDER, 2013). Apesar da grande quantidade de material espalhada pelo Brasil e pelo mundo, esse material é de difícil acesso (DONATTI, 2013).

Existem nós em períodos da sua vida que não estão desatados e talvez estudos mais aprofundados sobre o antropólogo e o período político em que atuou pudessem abrir novos caminhos de análise (DONATTI, 2013) O primeiro nó seria sua amizade e sua relação profissional com o diretor do Museu Paulista, Hermann von Ihering, que incentivava o extermínio dos Caingang em 1907 e que suscitam dúvidas sobre quais foram os trabalhos etnográficos de Nimuendajú para o Museu Paulista (DONATTI, 2013).

Um segundo nó é sobre sua intenção de trabalho como pacificador no SPILTNServiço de Proteção aos Índios e Localização dos Trabalhadores Nacionais, junto ao Ministério da Agricultura, Indústria e Comércio que perdurou durante toda a sua vida no Brasil, desde o início daquele órgão em 1910 (LIMA, 2002; DONATTI, 2013).

Sabemos que durante o seu trabalho no SPILTN (Serviço de Proteção aos índios e localização dos Trabalhadores Nacionais), o governo teve interesse na miscigenação dos nativos, transformando-os em trabalhadores. Nesse período de pacificação, houve a destruição de diferentes povos nativos (OLIVEIRA FILHO, 1999; DONATTI, 2013).

O terceiro nó está relacionado às suas orientações sobre o povo Aparaí, moradores da região do Jari para a expedição nazista de 1935, liderada pelo zoólogo Schulz Kampfhenkel (comunicação pessoal com o Prof. Dr. Augusto Oyuela-Caycedo).

Não se sabe ao certo o interesse nazista sobre os nativos, além de coletas de flora, fauna, objetos etnográficos e produção de filmes (STOECKER, 2013). Também, relacionado a ideologia nazista, Nimuendajú foi acusado e preso em 1942, em Manaus, mas pouco se sabe sobre esse episódio (GRUPIONI, 1998; DONATTI, 2013).

Esse lado obscuro de Nimunedajú ainda é pouco conhecido, mas deve-se reconhecer que houve uma participação intensa na pacificação junto ao SPILTN, no 


\section{Revista de Arqueologia Pública}

colecionismo para museus e para particulares, bem como na produção da imagem de um índio que foi aniquilado.

\section{O Holocausto como figura de linguagem}

A partir do começo de 1980, os discursos sobre memória aceleraram-se na Europa e nos Estados Unidos com o debate sobre o Holocausto (HUYSSEN, 2000). No final de 1990, já havia uma globalização do discurso do Holocausto. Segundo Hyussen (2000), políticas genocidas em Ruanda, na Bósnia e em Kossovo, na década de 1990, fizeram com que o discurso do Holocausto permanecesse vivo. A intervenção humanitária da OTAN em Kossovo e sua legitimação foram dependentes do Holocausto. Para Huyssen, "o Holocausto serve como prova da incapacidade da civilização ocidental de praticar anamnese, de refletir sobre sua inabilidade constitutiva para viver em paz com diferenças e alteridades e de tirar as consequências das relações insidiosas entre a modernidade iluminista, a opressão racial e a violência organizada" (HUYSSEN, 2000: 13).

O autor analisa a emergência do Holocausto como uma figura de linguagem universal que permite à memória do Holocausto entender situações locais específicas, historicamente e politicamente distantes do evento original, começando a funcionar como uma metáfora para outras histórias e memórias (HUYSSEN, 2000).

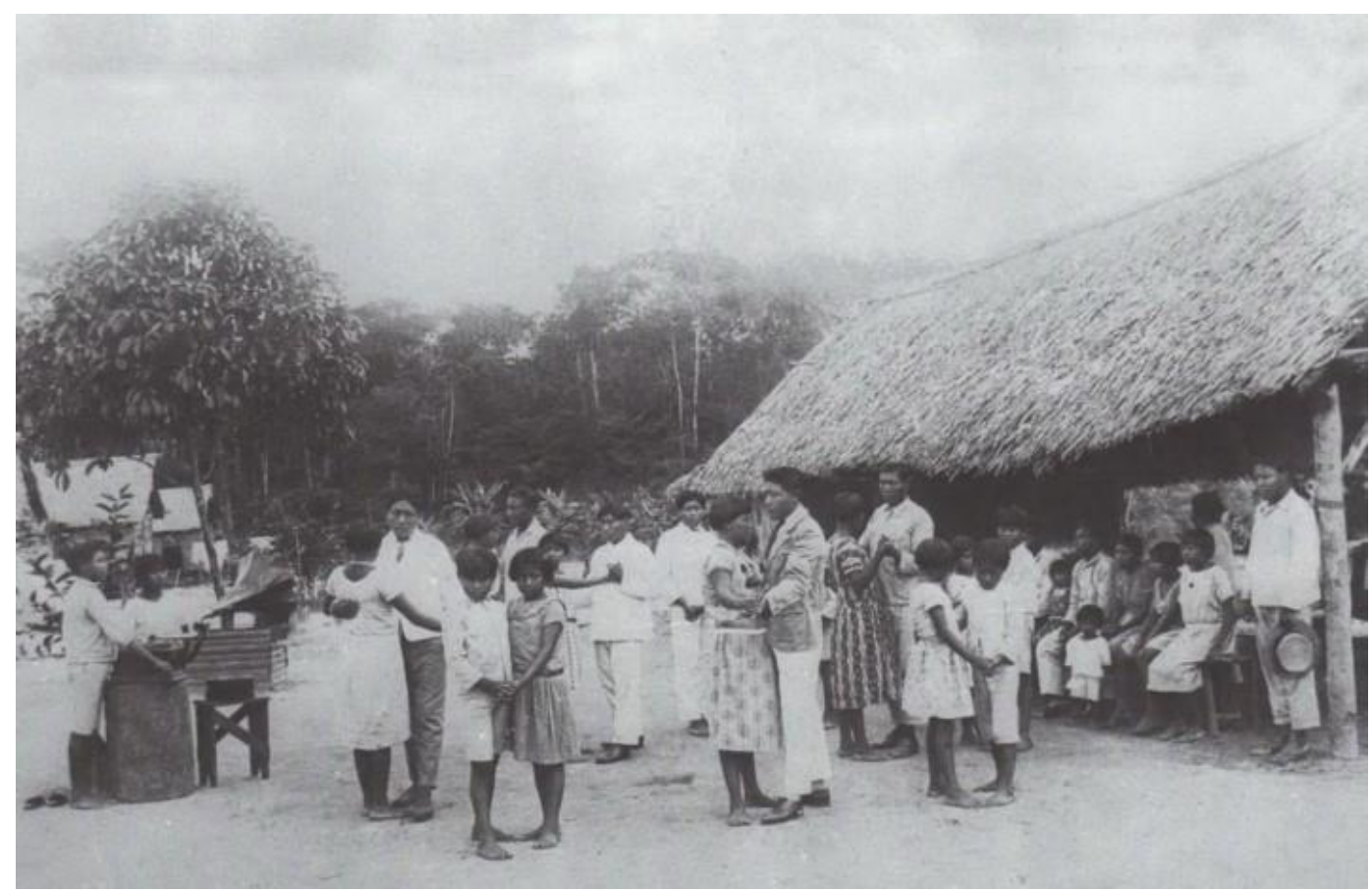

Figura 2: Fotografia do Povo Parintintin pacificado, 28/05/1922 (FREIRE, 2007: 97). 


\section{Revista de Arqueologia Pública}

Assim, as histórias dos nativos e de seu genocídio deveria ser reescrita, como, por exemplo, sobre a pacificação dos povos Parintintin (Figura 2). Rememorar essas histórias seria tentar evitá-las no futuro.

"O Holocausto, como lugar comum universal, é o pré-requisito para seu descentramento e seu uso como um poderoso prisma através do qual podemos olhar outros exemplos de genocídio" (HUYSSEN, 2000: 13). Segundo Huyssen (2000), o global e o local da memória do Holocausto podem ser analisados em diferentes casos e períodos, valorizando retoricamente discursos de memória traumática. Ao analisar a fotografia do povo Parintintin pacificado, consideramos que os resquícios dos pacificadores como Nimunedajú e do Serviço de Proteção ao Índio e localização dos Trabalhadores Nacionais (Figura 2) estão presentes de forma heróica na História da Antropologia /Arqueologia Brasileira. História essa organizada em museus, universidades e pessoas que lucraram com o genocídio nativo.

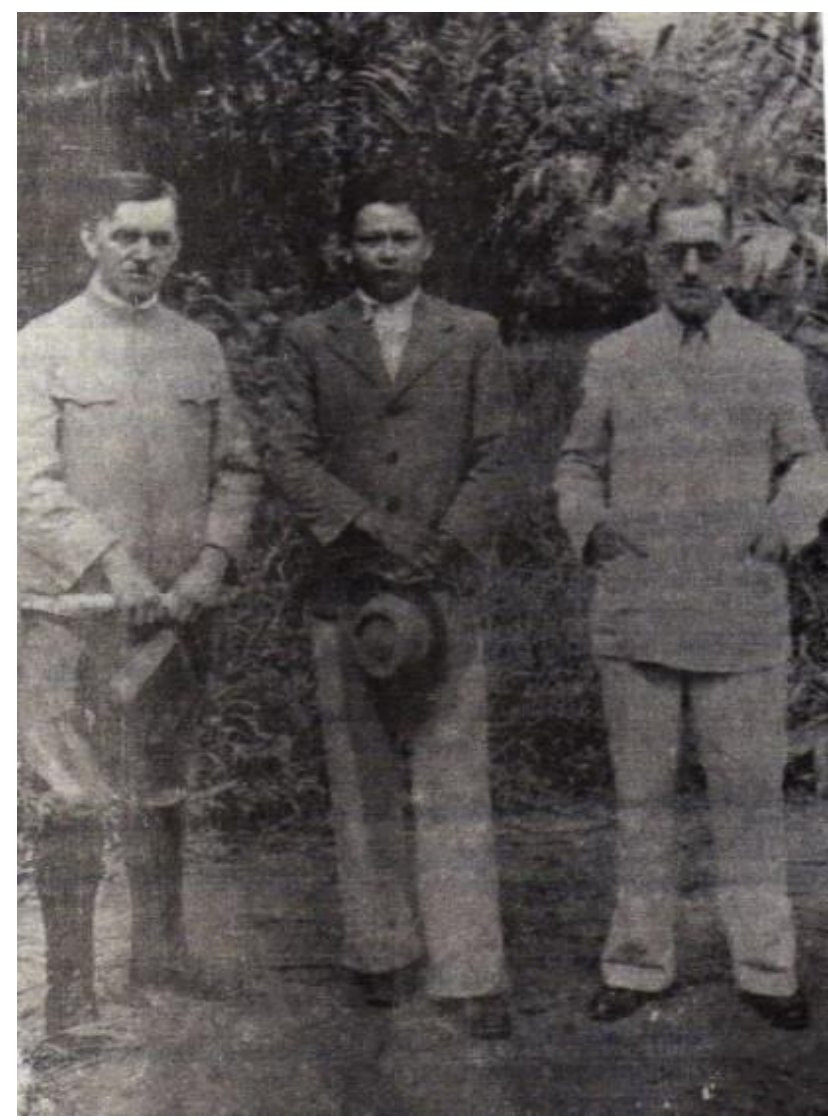

Figura 3: Curt Nimuendajú à esquerda, ao centro o mestiço, e Carlos Estevão de Oliveira à direita. Foto sem procedência nem data (TORRE e DAMY, 1990: 183). 


\section{Revista de Arqueologia Pública}

Por exemplo, nas figuras 3 e 4, Nimuendajú é registrado com o amigo Carlos Estevão de Oliveira, colecionador e diretor do Museu Paraense Emílio Goeldi entre 1930 a 1946. Carlos Estevão facilitava os trabalhos Nimuendajú de envio de material para o Brasil e exterior e Nimuendajú montava as coleções para Carlos Estevão (NIMUENDAJÚ, 2000).

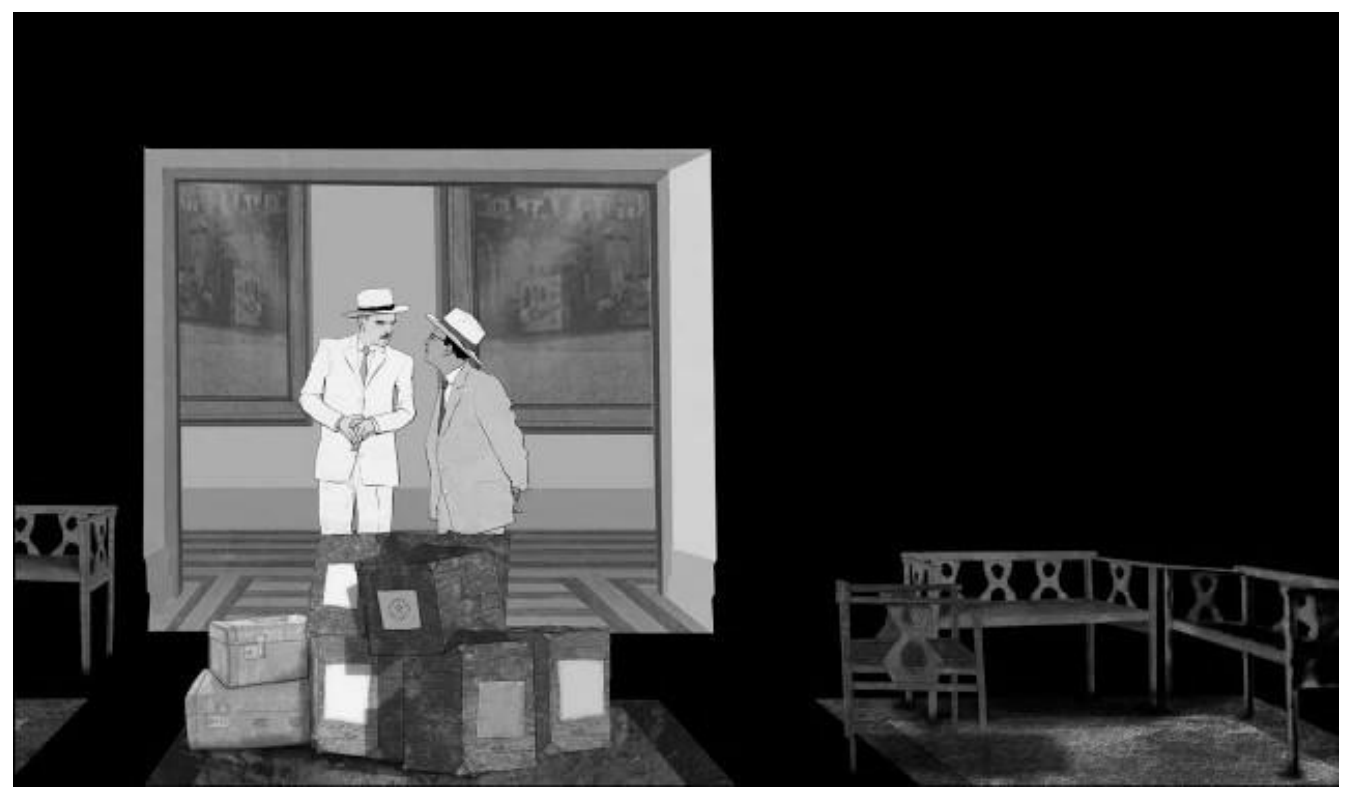

Figura 4: Cena do filme "Nimuendajú". À esquerda Curt Nimuendajú e à direita o amigo colecionador Carlos Estevão de Oliveira.

O olhar do antropólogo/arqueólogo também é crucial no entendimento da sua projeção de colonizador sobre o nativo/colonizado. Na fotografia de Nimuendajú (Figura 5), ele capta o momento do banho de crianças, homens e mulheres, juntos. À esquerda, um grupo se diverte sem prestar atenção no fotógrafo. No entanto, no centro da imagem, três adultos se voltam para o fotógrafo no momento do disparo. 


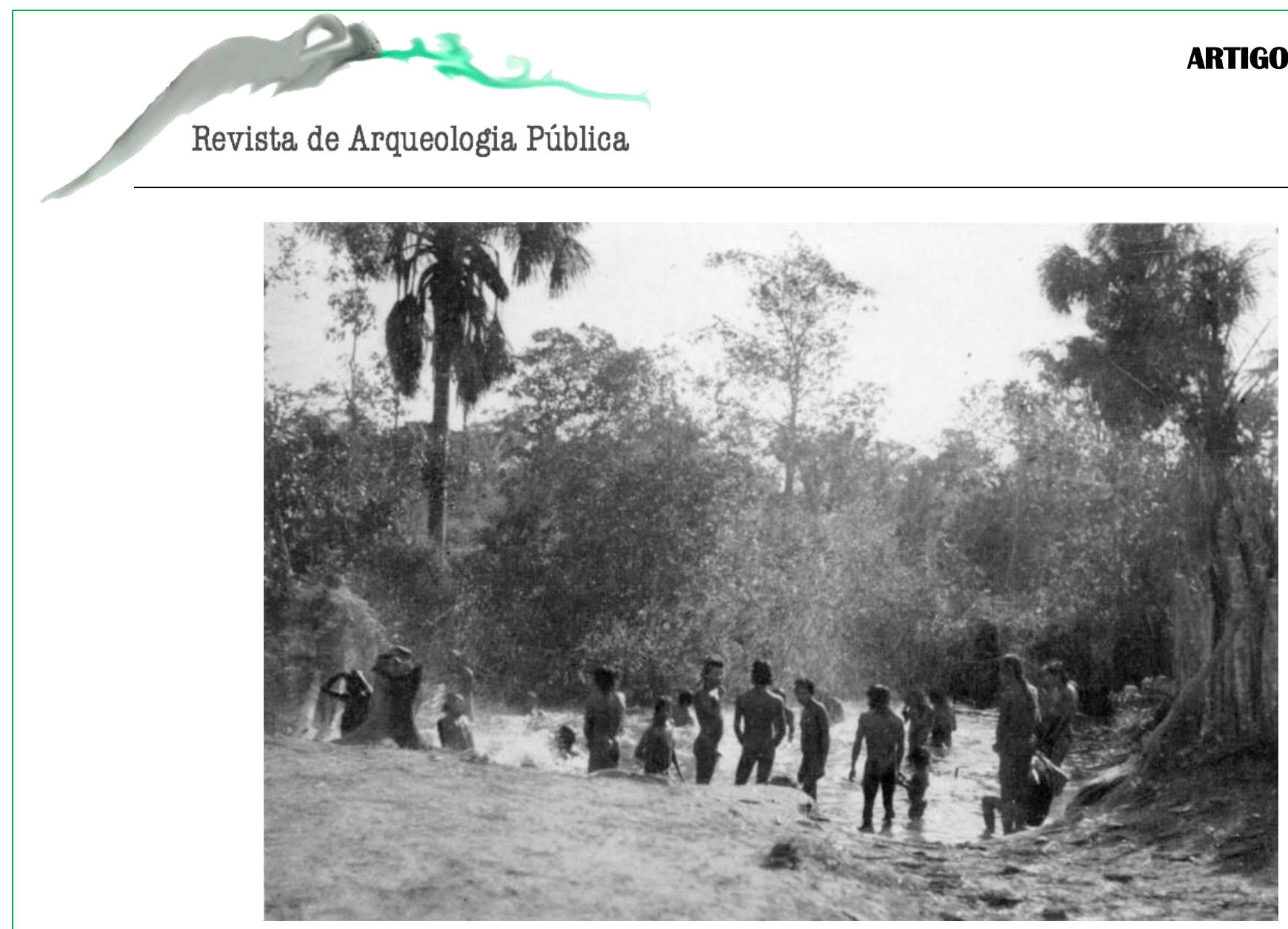

Figura 5: Fotografia de Curt Nimuendajú da aldeia do Ponto, Canela²

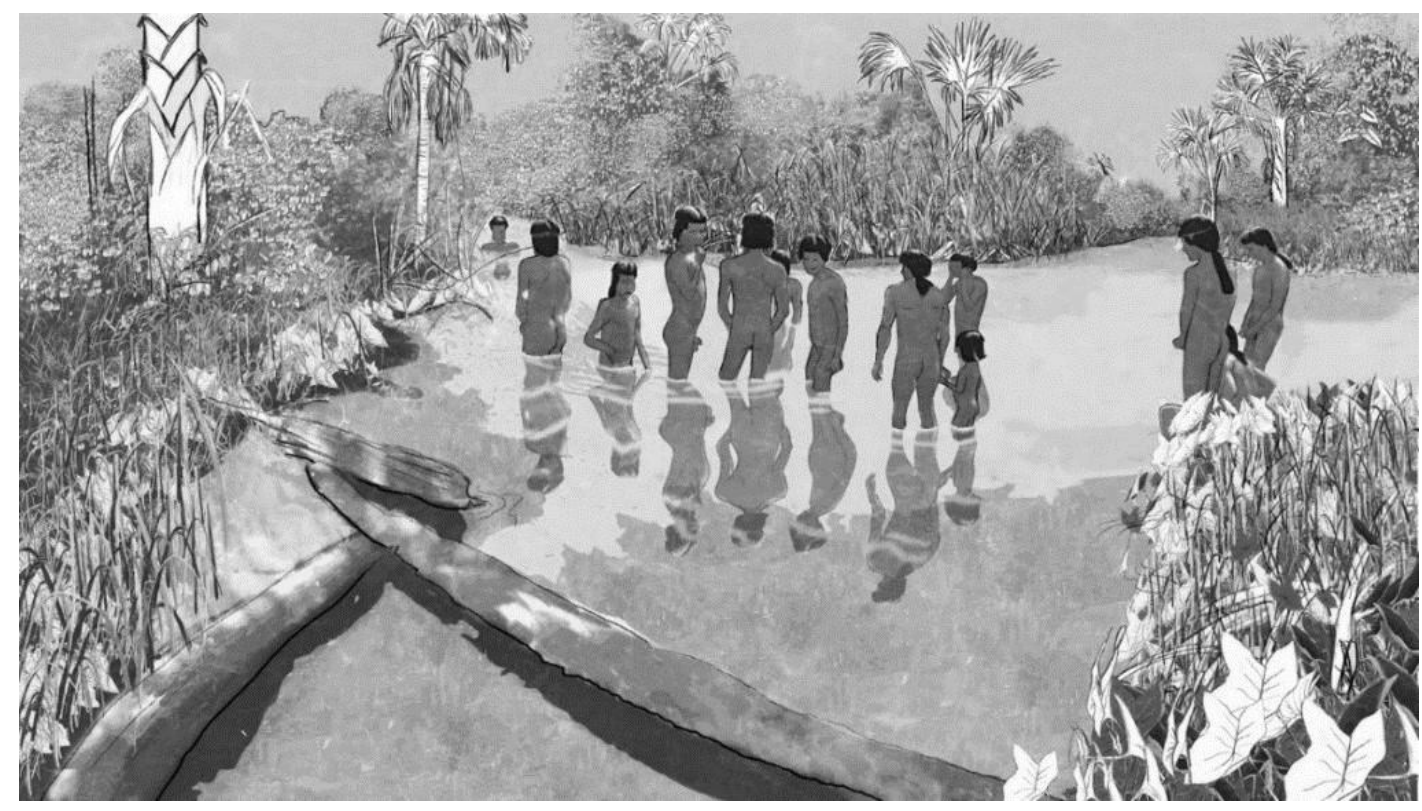

Figura 6: Cena do filme "Nimuendajú". Aldeia do Ponto, Canela.

2 Página da Internet acessada em 22 de abril de
2015.http://filmenimuendaju.blogspot.com.br/p/galeria.html




\section{Revista de Arqueologia Pública}

Na Figura 6, a cena do banho na aldeia do Ponto do povo Canela é quase uma cópia da fotografia original de Nimuendajú. No entanto, a cena oculta o realismo da foto e introduz elementos como a sombra, a transparência e a tranquilidade da água do rio, diferente da fotografia original; trazendo um referencial onírico sobre a "vida selvagem". A fotografia de Nimuendajú (Fig 5) mostra um discurso de quem está acima da situação; do antropólogo/arqueólogo com uma posição de superioridade. Já a cena do filme (Fig 6) possui um discurso de memória que retoma a visão dos nativos como natureza, selvagem marcando a visão do Outro $^{3}$ como aquele que é diferente, inferior. Esse discurso enfatiza novamente a posição do colonizador e do colonizado.

\section{Considerações finais}

A memória sobre Nimuendajú que está disseminada na sociedade e na academia nos dias atuais ainda toma Nimuendajú como o herói ligado a instituições que destruíram populações nativas. Através da perspectiva do Holocausto de Huyssen que relacionou mídia, política e amnésia sobre casos diversos de extermínio que ocorreram e ocorrem no mundo, em diferentes períodos e que ainda estão presente na História, comparo as práticas de Nimuendajú ligadas ao genocídio nativo no Brasil cujas ideias são reproduzidas no presente.

\section{Referências bibliográficas}

ARNAUD, Expedito. Curt Nimuendaju: Aspectos de sua vida e de sua obra. Revista do Museu Paulista, V. XXIX (1983-1984), p. 55-72.

BALDUS, Herbert. Curt Nimuendaju, 1883-1945. American Anthropologist. V. 48, (1946), p. 238-243.

CORREA, Mariza. An Interview with Roberto Cardoso de Oliveira. Current Anthropology. Vol. 32, no. 3 (1991), p. 335-343.

CRULS, Gastão. Hiléia Amazônica. Belo Horizonte: Editora Itatiaia, 2003.

DONATTI, Patrícia Bayod. As Políticas da Antropologia Brasileira: o caso de Curt Nimuendajú. Curitiba: Editora Appris, 2013.

\footnotetext{
${ }^{3}$ Johannes Fabian analisa o termo Outro na Antropologia como aquele que é inferior, em seu livro Time and the Other: how anthropology makes its object. New York: Columbia University Press. 1983
} 


\section{Revista de Arqueologia Pública}

FABIAN, Johannes. Time and the other: how anthropology makes its object. New York: Columbia University Press, 1983.

FAULHAUBER, Priscila. Conexões internacionais na etnografia de Nimuendajú. Revista de Antropologia. V.56, no.1 (2013), São Paulo: Universidade de São Paulo. p. 207-256.

FREIRE, Carlos Augusto da Rocha. O SPI na Amazônia: Política Indigenista e conflitos regionais (1910-1932). Publicação Avulsa do Museu do Índio, no. 2 (2007), 115p.

GORDON JR, Cesar C. Aspectos da organização Gê: de Nimuendajú a década de 90. Dissertação de mestrado. Programa de pós-graduação em Antropologia Social do Museu Nacional/ Universidade Federal do Rio de Janeiro, 1996.

GRUPIONI, Luiz Donisete Benzi. Coleções e expedições vigiadas: Os etnólogos no Conselho de Fiscalização das Expedições Artísticas e Científicas no Brasil. São Paulo: Hucitec/Anpoc, 1998.

HUYSSEN, Andrea. Seduzidos pela memória: arquitetura, monumentos, mídia. Aeroplano: Rio de Janeiro, 2000.

LARAIA, Roque de Barros. A morte e as mortes de Curt Nimunedajú. Série Antropologia. Brasília: Fundação da Universidade de Brasília, no. 64 (1988), p.9.

LÉVI-STRAUSS, Claude. Structural Anthropology. Vol. 2. Chicago: The University of Chicago Press, 1983.

LIMA, Antonio Carlos de Souza. O governo dos Índios sob a gestão do SPI. In CUNHA, Manuela Carneiro da. História dos Îndios no Brasil. São Paulo: Companhia das Letras, 1992, p. 155-172.

LOWIE, Robert. Robert Lowie, ethnologist: A personal record. California: University of California Press, 1959.

NIMUENDAJÚ, Curt. As lendas de criação e destruição do mundo como fundamentos da religião dos Apopocúva-Guarani. São Paulo: HUCITEC/ Universidade de São Paulo, 1987.

Cartas do Sertão: De Curt Nimuendaju para Carlos Estevão de Oliveira. Lisboa: Assírio e Alvim, 2000.

In pursuit of a past Amazon: Archaeological researches in the Brazilian Guyana and in the Amazon Region. Göteborg: Elanders Infologistik Väst $A B$, 2004.

OLIVEIRA FILHO, João Pacheco. Ensaios em Antropologia Histórica. Rio de Janeiro: Editora UFRJ, 1999.

PEREIRA, Nunes. Curt Nimuendajú: Síntese de uma vida e de uma obra. Pará: Gráficas da Veterinária, 1946.

SCHADEN, Egon. The Tukuna. Curt Nimuendaju. American Anthropologist, V.55 (1953), p. 716-718.

\begin{tabular}{|l|l|l|l|l|l|l|}
\hline (C) Rev. Arqueologia Pública & Campinas, SP & v. 10 & n. 3 & p. 81-90 & OUT. 2016 & ISSN 2237-8294
\end{tabular}




\section{Revista de Arqueologia Pública}

SCHRÖDER, Peter. Curt Unkel Nimuendajú: um levantamento bibliográfico. Tellus, Ano 13, n. 24, (2013). Campo Grande: Universidade Católica Dom Bosco, p. 39-76.

STOECKER, Hoelger. The riddle of hell's jungle. In BELL, Joshua A; Brown, Alison K.; GORDON, Robert J. Recreating first contact: expeditions, anthropology and first contact. Washington: Smithsonian Institution Press, 2013, p. 162-183.

TORRE, Sandra de la; Damy, Antonio Sérgio Azevedo. Comunicações: Cartas de Curt Nimuendajú a Carlos Estevão de Oliveira. Revista de Antropologia. Vol. .33 (1990). São Paulo: Universidade de São Paulo, p. 165-198.

VAINFAS, Ronaldo. A Heresia dos índios: Catolicismo e rebeldia no Brasil colônia. São Paulo: Companhia das Letras, 1995.

WELPER, Elena Monteiro. Curt Unkel Nimuendajú: um capítulo alemão na tradição etnográfica brasileira. Dissertação de mestrado. Rio de Janeiro: Museu Nacional/ Universidade do Rio de Janeiro, 2002.

A aventura etnográfica de Curt Nimunedajú. Tellus, ano 13, n.24 , (2013). Campo Grande: Universidade Católica Dom Bosco, p. 99-120. 